\title{
¿Cómo la negociación colectiva puede ayudar a reducir el absentismo en las empresas?
}

\author{
Jordi Garcia Viña \\ Profesor Titular de Derecho del Trabajo y de la Seguridad Social \\ Universitat de Barcelona
}

Recibido: 08.01 .2010

Aceptado: 13.04.2010

\begin{abstract}
Resumen: Uno de los problemas importantes en el mundo de las relaciones laborales de los últimos años es el aumento del absentismo laboral. El empresario, de repente, observa que los puestos de trabajo están vacíos, con los consiguientes problemas que esta situación supone, sin que conozca las causas de estas ausencias, ni pueda poner remedio. Las empresas necesitan solucionar esta situación tan grave que tantas consecuencias negativas tiene para su competitividad. Una de las posibilidades radica en introducir, por medio de la negociación colectiva, cláusulas que generen mayor flexibilidad en la prestación laboral y que suponga un beneficio, no solo para el empresario, sino también para el trabajador.
\end{abstract}

Palabras clave: Negociación colectiva, absentismo, empresa.

Abstract: One of the important problems in the world of the labour relations of the last years is the increase of the labour absenteeism. The employer, suddenly, observes that the workplaces are empty, with the consequent problems that this situation supposes, without knowing the causes of these absences, with no remedy. The companies need to solve this serious situation that has so many negative consequences for their competitiveness. One of the possibilities lies in entering, by means of the collective bargaining, clauses that generate main flexibility in the labour relationship and that suppose a profit, no only for the employer, but also for the employee.

Key words: Collective bargaining, absenteeism, company.

Sumario: 1. Cuestiones generales.-2. El absentismo en Europa.3. El absentismo en España.-4. El coste del absentismo.-5. Planes de resolución del absentismo.-6. Conclusiones.

\section{Cuestiones generales}

Uno de los primeros problemas con los cuales se encuentra cualquier persona cuando pretende definir qué es el absentismo es que no existe unanimidad sobre la definición de este concepto. Normalmente, se suele partir de definiciones amplias del absentismo, como, por ejemplo, las horas no trabajadas totales, o bien han excluido algunos conceptos que claramente no tienen que ver con el absentismo. 
Así, cabe citar las siguientes tres definiciones:

- La ausencia del trabajador, que es involuntaria y puede responder a diversas causas (enfermedad, accidente, fuerza mayor, etc.).

- El tiempo no trabajado, que constituye un derecho social para el trabajador (maternidad y otros permisos remunerados, formación, etc).

- El absentismo de carácter voluntario, como, por ejemplo, los retrasos. Este absentismo injustificado también puede ocultarse bajo otras figuras, como la incapacidad temporal, haciendo uso de los denominadas «falsas bajas», o bien de una enfermedad sin baja.

Con respecto a las consecuencias económicas del absentismo para las empresas y para el trabajador, pueden aparecer tres situaciones:

- El absentismo injustificado. La empresa no abona la remuneración correspondiente y el trabajador, por lo tanto, deja de percibir el salario del tiempo de absentismo.

- La enfermedad sin baja. Si el convenio colectivo lo prevé, la empresa continúa pagando una parte o toda la remuneración del trabajador. A partir del cuarto día es obligatorio presentar la baja, y consecuentemente se pasa a situación de incapacidad temporal.

- La incapacidad temporal. Hasta el decimoquinto día la empresa paga un $60 \%$ del salario y, a partir de este momento, la Seguridad Social asume el pago de un $75 \%$ del salario del trabajador. En algunos casos, si lo estipula el convenio colectivo, la empresa puede complementar esta percepción. Si la incapacidad temporal es causada por enfermedad profesional o accidente laboral, la prestación corre a cargo de la Seguridad Social.

Por otro lado, el absentismo depende de un número considerable de factores; en este sentido, si una empresa cuenta con unas condiciones laborales favorables, ofrece incentivos y promoción para los trabajadores, consigue un buen clima laboral y, en definitiva, gestiona bien sus recursos humanos, es muy probable que cuente con unos niveles más bajos de absentismo laboral.

En los últimos años se está produciendo un aumento del absentismo laboral, por lo cual varias empresas están aplicando planes para reducirlo mediante el aumento del nivel de satisfacción de los trabajadores, el seguimiento individual de los objetivos a cumplir por parte del trabajador y dando flexibilidad horaria que permita conciliar la vida laboral con la personal. El uso de las nuevas tecnologías puede ser muy importante para conseguir esta flexibilidad.

Asimismo, como se trata de una ausencia no programada, pueden aparecer costes adicionales cuando sea necesario sustituir al trabajador, costes que dependen, fundamentalmente, del tipo de trabajo que desarrolle este y de la propia actividad de la empresa. 
En definitiva, y este es uno de los principales problemas para las empresas, el absentismo laboral comporta, entre otras, las siguientes consecuencias, unos costes económicos directos para la empresa, y, al mismo tiempo, puede generar otros efectos negativos que se podrían catalogar como indirectos, como, por ejemplo, una menor productividad o un mal ambiente entre los trabajadores.

\section{El absentismo en Europa}

Uno de los trabajos más interesantes sobre el tema es el estudio sobre absentismo laboral realizado en el año 2007 por PricewaterhouseCoopers en más de 16.000 empresas europeas, que compara los niveles de absentismo en diferentes países europeos. En este estudio la ratio de absentismo que se utiliza se define como los días u horas no trabajados o perdidos entre el total de días de trabajo disponibles. Dentro de las horas no trabajadas se incluye la incapacidad o enfermedad, las huelgas y los permisos familiares, pero no se considera la maternidad ni las horas no trabajadas por regulación de empleo. Los días de trabajo disponibles incluyen los días efectivamente trabajados, las horas extraordinarias y las horas no trabajadas o perdidas.

Francia y Alemania lideran el ranking europeo del absentismo laboral, con un $4,5 \%$ y un 4,4\%, respectivamente. En relación con España, no se ofrecen datos específicos para el país, pero la información disponible para el conjunto de España y Portugal revela una tasa de un 4,1\%, algo por encima de la media europea (4\%) y de la media de la Europa Occidental $(3,9 \%)$. Los países con menor absentismo son Italia y Austria.

Los sectores de actividad de Europa con una tasa de absentismo más elevada son la industria química y los seguros, seguidos del sector público. Por el contrario, los porcentajes más bajos corresponden a la electrónica y a las nuevas tecnologías. Con respecto a la dimensión empresarial, se señala que las compañías pequeñas y medianas con plantillas de menos de 1.000 personas presentan las menores ratios de absentismo.

El absentismo de los directivos en Europa es de un 2,1\%, en comparación con un $4 \%$ del total de los trabajadores. Además, los directivos con una ratio más elevada son los del sector público y los de los seguros, mientras que los que presentan unos porcentajes más bajos corresponden a la electrónica y a las nuevas tecnologías.

\section{El absentismo en España}

Según la Encuesta de Coyuntura Laboral del Ministerio de Trabajo y Asuntos Sociales, en el año 2008 el número de horas no trabajadas por causas ocasionales ascendió a 60,7 horas por trabajador. Esto representa un aumento de un $6,5 \%$ respecto al 2007 , lo cual supone acelerar la subida registrada el ejercicio pasado, cuando el incremento se situó en un 3,1\%. 
La principal causa del absentismo laboral es la incapacidad temporal, que incluye enfermedades por causas comunes y accidentes no laborales, así como enfermedades y accidentes laborales. A efectos de la Encuesta de Coyuntura Laboral, dentro de la incapacidad temporal también se incluyen las enfermedades y accidentes, aunque sean de duración inferior a los tres días y no generen baja De las 60,7 horas no trabajadas por ocupado, un $71,7 \%$, es decir, 43,5 horas, fueron causadas por este concepto. De hecho, el comportamiento de las horas no trabajadas ocasionales depende, fundamentalmente, de cómo evoluciona la incapacidad temporal. Otras razones de absentismo son el permiso de maternidad -que supuso 6,8 horas por trabajador-, y otros permisos remunerados -que representan 4,4 horas-, seguidos de la formación, las actividades de representación sindical y el absentismo injustificado.

En los últimos años se está produciendo un aumento del número de horas no trabajadas dedicadas a la formación y a los permisos remunerados, lo cual sugiere que los empresarios podrían estar dando más importancia a la formación y a la conciliación de los trabajadores como factor competitivo. Aun así, los datos más recientes parecen romper con esta tendencia de incremento continuo en el caso de la formación. Con respecto al absentismo injustificado, se ha de mencionar que también ha registrado un crecimiento notable como causa de absentismo a lo largo de los últimos años. En 2006, por ejemplo, las horas no trabajadas por este concepto se incrementaron un 15,4\%, y los datos del 2007 señalan el mantenimiento de esta alza.

En el año 2008 se estima que la tasa de absentismo se situó en un 3,6\% de la jornada teórica total. La evolución de esta en la pasada década hace patentes dos etapas bien diferenciadas. En el período 1997-2000 se produjo un descenso en la tasa de absentismo, pero desde el año 2000, cuando la tasa fue de un 2,6\%, ha tenido lugar un incremento lento pero sostenido. Los datos correspondientes al tercer trimestre de 2007 muestran que la tasa de absentismo se situó en un 3,9\%.

Tasas del 3,6\% o del 3,9\% se podrían considerar relativamente bajas si se tiene en cuenta la notable preocupación que suscita la problemática del absentismo desde la órbita empresarial. En este sentido, la Encuesta de Coyuntura Laboral tiene como objetivo reflejar la evolución del mercado laboral y no medir el absentismo, que se calcula a través de una estimación indirecta, por lo cual los resultados que se obtienen en esta materia siempre se deben considerar con prudencia. Por otro lado, la Encuesta solo se centra en los trabajadores del régimen general, y excluye sectores como la agricultura, la administración pública, defensa y seguridad social.

En otro sentido, es importante destacar las diferencias que puede haber en el cálculo de lo que se considera absentismo; estas diferencias también aconsejan prudencia en el análisis de la problemática según los datos disponibles. Internacionalmente, tampoco existen metodologías armonizadas 
y, de hecho, organismos estadísticos como Eurostat no publican datos al respecto correspondientes a países europeos. La comparación es difícil, porque influyen muchos factores, como los relativos a los sistemas de sanidad y de seguridad social, al mercado de trabajo y a la cultura empresarial (si existe flexibilidad horaria, si hay simplemente un control de presencia o, por el contrario, se establecen objetivos y se evalúan los resultados, etc.).

Finalmente, hay que apuntar que la tasa de absentismo es un indicador que mide parcialmente la magnitud de la problemática, puesto que tasas relativamente reducidas de absentismo pueden ocultar grandes inconvenientes para las empresas que los registren: por ejemplo, en algunas ramas industriales la ausencia de trabajadores que ocupen determinados puestos de trabajo bastantes cualificados y, por lo tanto, difícilmente sustituibles, puede suponer un problema importante para la producción.

La tasa de absentismo es más elevada entre los trabajadores con jornada completa que entre quienes trabajan a tiempo parcial. En el año 2008 la tasa de absentismo de los efectivos con jornada completa fue de un 3,7\%, mientras que en el colectivo con jornada parcial se situó en un $2,4 \%$. Tal y como sucedía con la tasa de absentismo media, desde el año 2000 se ha producido un incremento gradual de la tasa de absentismo en todos los tipos de jornadas (del 2,7\% al 3,7\% en el caso de la jornada completa, y del 1,3\% al 2,4\% en el caso del tiempo parcial).

El sector económico con un mayor número de horas no trabajadas por causas ocasionales es la industria, que en 2008 sufrió la pérdida de 75,8 horas no trabajadas por efectivo. Le siguen los servicios (60,4 horas) y, en último lugar, la construcción (43,1 horas). Aun así, el mayor incremento durante el año 2008 correspondió a los servicios, en que las horas no trabajadas crecieron un $8,8 \%$ anual.

La tasa de absentismo en la industria era de un $4,3 \%$, frente a un $3,6 \%$ por el total de la economía. Por otra parte, en los servicios se situaba en el $3,7 \%$ y en la construcción, en el 2,4\%. En comparación con el 2000, se ha de mencionar un incremento generalizado del absentismo en todos los sectores de actividad, si bien el crecimiento ha sido más intenso en el caso de los servicios, en que ha aumentado 1,2 puntos porcentuales en el período 2000-2008. El crecimiento absoluto ha sido algo menor en la industria (subida de un punto porcentual) y más reducido en la construcción (incremento de 0,5 puntos).

La tasa de absentismo es más elevada en las empresas más grandes, en las que, lógicamente, resulta más compleja la gestión de los recursos humanos. Es de un 5,6\% en las empresas de más de 250 trabajadores, de un 4,1\% en las que tenían entre 51 y 250 trabajadores, de un $2,9 \%$ en las que contaban entre 11 y 50 trabajadores, y de un $2,1 \%$ en las que tenían 10 o menos trabajadores. La tasa ha tendido a aumentar en todos los colectivos a lo largo de los últimos cinco años, pero en términos relativos se ha incrementado más en las empresas pequeñas, donde la tasa casi se ha duplicado, de un 
$1,1 \%$ en 2000 hasta un 2,1\% en 2008. Esta distribución del absentismo guarda relación con el comportamiento por sectores, dado que la industria, sector en el cual la dimensión empresarial es, en líneas generales, superior era la que presentaba una tasa de absentismo más alta.

En el año 2008, las comunidades autónomas que contaban con un mayor número de horas ocasionales no trabajadas por trabajador eran, también, las que presentaban una tasa de absentismo más elevada. El porcentaje más alto correspondía a Asturias, con una tasa de un 4,6\% y un número de horas no trabajadas de 76,6 por trabajador. La seguían el País Vasco y Cantabria, con tasas de un $4,5 \%$ y de un $4,1 \%$ respectivamente. Por el contrario, la tasa más reducida, con diferencia, era la de Extremadura, de un $2,7 \%$. Esta situación se mantiene desde hace años, dado que en 2000 eran las comunidades autónomas mismas las que presentaban los niveles más altos y más bajos. Justo es decir, no obstante, que en los últimos años se ha producido un ascenso generalizado del absentismo en todas las comunidades autónomas. En 2008 los incrementos más intensos correspondieron a Galicia, Navarra y Asturias, mientras que se produjo una reducción en Canarias y Murcia.

En cuanto a la incidencia específica de la incapacidad temporal, también se observan diferencias: así Cataluña presentaba una incidencia de la incapacidad temporal (3,5\% de los trabajadores protegidos) por encima de la media española (3\%). Los territorios con un menor porcentaje fueron Extremadura $(1,9 \%)$ y Andalucía $(3,3 \%)$. Con respecto a la duración media de los procesos, los más largos corresponden al País Valenciano y Murcia (por encima de los 60 días) y los más cortos a Baleares y Cataluña (43 días).

Es evidente que, con estas magnitudes, el absentismo se ha convertido en un problema, tanto para las empresas en particular, como para la sociedad en general. Se han propuesto varios mecanismos para solucionar esta situación, sin que ninguna de las partes implicadas (empresa, trabajador y sociedad) se vea perjudicada.

La negociación colectiva puede ayudar a mejorar esta situación. Son diversos los convenios colectivos que regulan aspectos, especialmente en relación con la jornada de trabajo, que claramente solventan factores relativos al absentismo. Sin embargo, son escasos los convenios colectivos que incluyen alguna cláusula que tenga incidencia directa en la solución de esta materia, como, por ejemplo, planes concretos de resolución del absentismo.

\section{El coste del absentismo}

El absentismo laboral genera un coste económico directo para las empresas que lo sufren, íntimamente relacionado con los pagos que hacen a los trabajadores ausentes durante el primer período de baja. Además, existe un coste indirecto asociado, básicamente, a dos hechos. En primer lugar, uno rela- 
cionado con la necesidad de sustituir a los trabajadores ausentes, circunstancia que puede implicar varios tipos de costes añadidos (búsqueda, contratación, formación, etc.). Y, de otra parte, uno asociado a la pérdida de eficiencia y de productividad que experimenta la empresa como consecuencia del absentismo de trabajadores en activo.

En España se estima que el coste económico directo de la incapacidad temporal para las empresas ascendió a 2.207 millones de euros en el año 2006, lo cual representa que las compañías abonaron por término medio unos 13 euros mensuales a cada trabajador en concepto de incapacidad temporal. Por otro lado, el resto de horas no trabajadas por absentismo (absentismo injustificado, permisos, etc.) supuso un coste de 1.838 millones de euros. Consecuentemente, el absentismo laboral generó, a lo largo de 2008, un coste directo total de 4.046 millones de euros, lo cual representa el 0,4\% del PIB y el 0,9\% de la masa salarial global (remuneración de los asalariados). Se estima que en Cataluña, que cuenta con unos costes laborales más elevados que la media española, el absentismo representó un impacto económico de 912,5 millones de euros, es decir, un 22,5\% del total estatal.

A partir de los datos procedentes de diferentes fuentes consultadas, se estima que, aproximadamente, la mitad de las horas no trabajadas por incapacidad laboral no se cubre con personas sustitutas, mientras que un $30 \%$ se hace con trabajadores de la misma empresa y con la realización de horas extraordinarias, y el restante $20 \%$ con efectivos contratados temporalmente.

En 2008 el absentismo laboral que se registró en España generó un impacto global sobre las empresas de 10.568 millones de euros, sin tener en cuenta la incidencia económica derivada de las pérdidas de eficiencia y de productividad asociadas al fenómeno. Esto representa un 1,1\% del PIB y un 2,3\% de la masa salarial global (remuneración de los asalariados).

\section{Planes de resolución del absentismo}

Los convenios colectivos no suelen regular planes de resolución del absentismo. De hecho, del total de los convenios colectivos analizados, solo el $3.9 \%$ contiene alguna cláusula que se refiere a medidas de acción positiva en materia de conciliación de la vida familiar y laboral, de los cuales, el $50 \%$ son convenios colectivos que regulan las prestaciones en ayuntamientos, tanto para el personal laboral como para los funcionarios, además de convenios de consejos comarcarles o de empresas participadas por la Administración pública, como, por ejemplo, la Agencia Catalana del Agua o el Consorcio del Museo de Arte Contemporáneo de Barcelona (MACBA). 
Convenios de empresa y sector vigentes que regulan el absentismo laboral en Cataluña (2008)

\begin{tabular}{|c|c|c|c|c|c|c|}
\hline \multirow[t]{2}{*}{ Ámbito } & \multicolumn{2}{|c|}{ Núm. Expedientes } & \multicolumn{2}{|c|}{ Trabajadores } & \multicolumn{2}{|c|}{ Empresas } \\
\hline & Abs. & $\%$ & Abs. & $\%$ & Abs. & $\%$ \\
\hline \multicolumn{7}{|l|}{ Negociación } \\
\hline Empresas & 153 & 15,10 & 33.105 & 1,80 & 157 & 0,10 \\
\hline Sector & 31 & 3,06 & 240.752 & 13,08 & 19.150 & 12,05 \\
\hline \multicolumn{7}{|l|}{ Territorial } \\
\hline Barcelona & 119 & 11,75 & 41.033 & 2,23 & 2.638 & 1,66 \\
\hline Girona & 11 & 1,09 & 16.509 & 0,90 & 3.224 & 2.03 \\
\hline Lleida & 3 & 0,30 & 241 & 0,01 & 3 & 0,01 \\
\hline Tarragona & 12 & 1,18 & 9.409 & 0,51 & 1.589 & 1,00 \\
\hline Cataluña & 8 & 0,79 & 24.572 & 1,33 & 1.672 & 1,05 \\
\hline Estatal & 31 & 3,06 & 182.093 & 9,89 & 10.181 & 6,41 \\
\hline \multicolumn{7}{|l|}{ Naturaleza jurídica } \\
\hline $\begin{array}{l}\text { Convenio } \\
\text { estatutario }\end{array}$ & 162 & 15,99 & 270.978 & 14,72 & 19.285 & 12,14 \\
\hline $\begin{array}{l}\text { Acuerdo y } \\
\text { pactos funcionarios }\end{array}$ & 22 & 2,17 & 2.879 & 0,16 & 22 & 0,01 \\
\hline Total general & 184 & 18,16 & 273.857 & 14,87 & 19.307 & 12,15 \\
\hline
\end{tabular}

De acuerdo con los datos del Departamento de Trabajo obtenidos del vaciado de todos los convenios colectivos vigentes en Cataluña en 2008, el $18,16 \%$ ha pactado alguna cláusula específica para la reducción del absentismo laboral. Estos convenios afectan al 14,87 \% de la población ocupada y el $12,15 \%$ de empresas de Cataluña reguladas por convenio colectivo, como se puede advertir en la tabla.

No obstante, si se procede a buscar dentro de los convenios las palabras «absentismo», «ausencia», «presencia» o «asistencia», solo el $75 \%$ de los convenios referenciados por el Departamento de Trabajo contemplaría cláusulas dirigidas a la reducción del absentismo.

Convenios reseñados por los responsables del vaciado que citen las palabras «absentismo», «ausencia», «presencia» o «asistencia»

\begin{tabular}{|l|rr|rr|rr|}
\hline \multirow{2}{*}{ Ámbito } & \multicolumn{2}{|c|}{ Regula conceptos } & \multicolumn{2}{|c|}{ No regula conceptos } & \multicolumn{2}{|c|}{ Total convenios } \\
\cline { 2 - 8 } & Abs. & \% Fila & Abs. & \% Fila & Abs. & \% Fila \\
\hline Empresa & 118 & 73,2 & 35 & 22,8 & 153 & 100 \\
Sector & 20 & 64,6 & 11 & 35,4 & 31 & 100 \\
\hline Total & $\mathbf{1 3 8}$ & $\mathbf{7 5 , 0}$ & $\mathbf{4 6}$ & $\mathbf{2 5 , 0}$ & $\mathbf{1 8 4}$ & $\mathbf{1 0 0}$ \\
\hline
\end{tabular}


Si se analizan las principales temáticas abordadas en aquellas cláusulas dirigidas a la reducción del absentismo laboral en los convenios de empresa, se constata la preeminencia de medidas dirigidas a incentivar el no absentismo a partir de otorgar pluses salariales a los trabajadores que no se ausentan como así pasa en un $46 \%$ de los convenios analizados.

Además, cabe citar la presencia de cláusulas dirigidas a definir de forma específica qué supone el absentismo en un $38,1 \%$ de los convenios. Con menos centralidad reguladora, se puede advertir que en el $25 \%$ de los convenios hay acciones dirigidas a la regulación específica de los incapacitados temporales; en un $23 \%$ de los casos, se adoptan acuerdos dirigidos a la mejora de la investigación del fenómeno y al establecimiento de sanciones a las prácticas absentistas, respectivamente.

Cuestiones como la adopción de sanciones que atañen a todos los trabajadores o a un grupo de estos por prácticas absentistas individuales son también relativamente importantes, y afectan al $16 \%$ de los convenios analizados. Por otra parte, la creación de comisiones, generalmente entre la empresa y los representantes de los trabajadores, está presente en un $14 \%$. Finalmente, se debe subrayar, además, el relativo poco peso de acciones dirigidas a incidir en la regulación del tiempo de trabajo, la organización del trabajo, los riesgos laborales y el control concreto de la existencia o no de prácticas absentistas. Finalmente, solo cinco casos entienden el absentismo como una cuestión clave para el negocio.

\section{Temáticas relacionadas con la regulación del absentismo laboral por parte de los convenios de empresa en Cataluña (2008)}

\begin{tabular}{|l|c|c|}
\hline Temática & $\begin{array}{c}\text { Número de } \\
\text { convenios }\end{array}$ & $\begin{array}{c}\text { \% Total } \\
\text { de convenios }\end{array}$ \\
\hline Plus salarial por no absentismo & 55 & 46,6 \\
Afecta pautas tiempos de trabajo (calendario, & 7 & 5,9 \\
jornada...) & 3 & 2,5 \\
Afecta pautas organización del trabajo (rotación, & 3 & 2,5 \\
categorías...) & 1 & 0,8 \\
Afecta selección y promoción personal & 30 & 25,4 \\
Despido & 28 & 23,7 \\
Regulación incapacitados temporales & 19 & 16,1 \\
Sanciones & 13 & 11,0 \\
Sanciones individuales asumidas colectivamente & 10 & 8,4 \\
Control & 8 & 6,7 \\
Control Incapacitado Temporal & 5 & 4,2 \\
Riesgos laborales & 45 & 38,1 \\
Elemento básico para estrategia de negocio & 27 & 22,8 \\
Definición absentismo & 17 & 14,4 \\
Investigación & $\mathbf{1 1 8}$ & $\mathbf{1 0 0}$ \\
Comisión & \multicolumn{2}{|c}{} \\
\hline Total &
\end{tabular}


Las cláusulas de los convenios sectoriales más destacables son los de definición concreta de las prácticas absentistas y la regulación específica de los incapacitados temporales, en un porcentaje de presencia en el conjunto de convenios similar al de empresa. Asimismo, se debe destacar la mayor importancia conferida a este tipo de convenios respecto a los de empresa en las cuestiones referidas a la realización de comisiones para su estudio y la consideración de los riesgos laborales como un elemento importante por incidir.

\section{Temáticas relacionadas con la regulación del absentismo laboral por parte de los convenios de sector en Cataluña (2008)}

\begin{tabular}{|l|c|c|}
\hline Temática & $\begin{array}{c}\text { Número de } \\
\text { convenios }\end{array}$ & $\begin{array}{c}\% \text { Total } \\
\text { convenios }\end{array}$ \\
\hline Plus salarial por no absentismo & 4 & 20,0 \\
Afecta pautas tiempos de trabajo (calendario, & 1 & 5,0 \\
$\quad$ jornada...) & 0 & 0,0 \\
Afecta pautas organización del trabajo (rotación, & 0 & 0,0 \\
$\quad$ categorías..) & 0 & 0,0 \\
Afecta selección y promoción personal & 6 & 30,0 \\
Despido & 2 & 10,0 \\
Regulación incapacitados temporales & 0 & 0,0 \\
Sanciones & 2 & 10,0 \\
Sanciones individuales asumidas colectivamente & 1 & 5,0 \\
Control & 4 & 20,0 \\
Control Incapacitado Temporal & 0 & 0,0 \\
Riesgos laborales & 7 & 35,0 \\
Elemento básico para estrategia de negocio & 0 & 0,0 \\
Definición absentismo & 7 & 35,0 \\
Investigación & 20 & 100,0 \\
Comisión & \multicolumn{2}{|c|}{} \\
\hline Total &
\end{tabular}

Finalmente, hay una serie de convenios que se pueden destacar en general para cada una de las cuestiones habitualmente reguladas cuando se aborda el absentismo laboral. Los distinguidos por incidir en una gran parte de estas cuestiones se han etiquetado en la casilla de «General» en la siguiente tabla. 


\section{Casos singulares de convenios colectivos de empresa y de sector por el nombre o tipo de cuestiones relacionadas con la regulación del absentismo laboral en Cataluña (2008)}

\begin{tabular}{|c|c|}
\hline General & $\begin{array}{l}\text { Eixide, Ayuntamiento de Terrassa, BSH, Delphi, } \\
\text { McDonalds, IT, Valeo Pirelli, Urbaser, Paradores, } \\
\text { Sectorial: Textil y Confección (estatal), Sectorial: } \\
\text { Químicas (estatal) }\end{array}$ \\
\hline $\begin{array}{l}\text { Plus salarial por } \\
\text { no absentismo }\end{array}$ & $\begin{array}{l}\text { Compañía de Aguas de Sabadell, Iberpotash, } \\
\text { La H } 2010 \text { La Vajilla, Sectorial: Salinera (Estatal), } \\
\text { Sectorial: Comercio de Juguetes (Barcelona) }\end{array}$ \\
\hline $\begin{array}{l}\text { Afecta pautas tiempos de } \\
\text { trabajo (calendario, } \\
\text { jornada...) }\end{array}$ & $\begin{array}{l}\text { Delphi, BSH, IACP, Telesco, Sectorial: Trabajadoras } \\
\text { familiares (autonómico) }\end{array}$ \\
\hline $\begin{array}{l}\text { Afecta pautas } \\
\text { organización del trabajo } \\
\text { (rotación, categorías...) }\end{array}$ & Delphi, Castellar Vidrios, Saint-Gobain \\
\hline $\begin{array}{l}\text { Afecta selección y } \\
\text { promoción personal }\end{array}$ & Delphi, Reno \\
\hline Despido & McDonalds \\
\hline $\begin{array}{l}\text { Regulación incapacitados } \\
\text { temporales }\end{array}$ & $\begin{array}{l}\text { Eixide, Fundación CIDOB, Pirelli, Sectorial: Bingo } \\
\text { (Estatal), Sectorial: Mataderos aves y conejos (Estatal). } \\
\text { Sectorial: Mueble (Cataluña) }\end{array}$ \\
\hline Sanciones & $\begin{array}{l}\text { General Cable, McDonalds, Sectorial: Pastas } \\
\text { alimenticias (estatal), Sectorial: Trabajadoras } \\
\text { familiares (Cataluña) }\end{array}$ \\
\hline $\begin{array}{l}\text { Sanciones asumidas } \\
\text { colectivamente por } \\
\text { prácticas individuales }\end{array}$ & TU, Valeo \\
\hline Control & $\begin{array}{l}\text { Eixide, Sectorial: Comercio de Juguetes (Barcelona), } \\
\text { Sectorial: Panaderías y hornos de pan (Tarragona) }\end{array}$ \\
\hline $\begin{array}{l}\text { Control Incapacitado } \\
\text { Temporal }\end{array}$ & $\begin{array}{l}\text { Ayuntamiento de Manresa, Sectorial: Pastas } \\
\text { Alimenticias (estatal) }\end{array}$ \\
\hline Riesgos laborales & $\begin{array}{l}\text { Ayuntamiento de Terrassa, BSH, Moderopa, Sectorial: } \\
\text { Tejas (estatal), Sectorial: Perfumería (estatal) }\end{array}$ \\
\hline $\begin{array}{l}\text { Elemento básico para } \\
\text { estrategia de negocio }\end{array}$ & Arcelor, Delphi, Ecoparc \\
\hline Definición absentismo & $\begin{array}{l}\text { Agencia Catalana del Agua, Celestica, General Cable, } \\
\text { Nestlé, Pirelli, Selmar, TÚ, Urbaser, Telesco, } \\
\text { Sectorial: Bingo (estatal), Sectorial: Mataderos aves y } \\
\text { conejos (estatal), Sectorial: Mueble (Catalunya), } \\
\text { Sectorial: Aceites (Barcelona) }\end{array}$ \\
\hline Investigación & Ayuntamiento de Calafell \\
\hline Comisión & $\begin{array}{l}\text { Ayuntamiento de Bahía, Rauscher, Virtisu, Sectorial: } \\
\text { Alimentación compuestos para animales (estatal), } \\
\text { Sectorial: Perfumería (estatal). }\end{array}$ \\
\hline
\end{tabular}


Los objetivos de estos planes, según los convenios colectivos, son claros, como se puede comprobar en los siguientes ejemplos:

\section{«Artículo 5.}

Objetivos

Son objetivos comunes de ambas partes la mejora de las condiciones de trabajo, la salud laboral, la productividad y competitividad de las empresas. Con este objetivo, estos deben colaborar a lograr los objetivos mencionados mediante el perfeccionamiento de los sistemas productivos y la reducción de los riesgos y del absentismo injustificado ${ }^{1} \gg$.

«Artículo 22.

Productividad

Conscientes las partes de la necesidad de conseguir una mejora general de la eficacia del sistema productivo para lo cual es necesaria la incorporación de todos los agentes de la producción, las partes consideran imprescindible aclarar los objetivos a lograr, así como los factores que inciden sobre estos y los instrumentos básicos para conseguirlo.

Los objetivos a lograr son:

Elevar la competitividad y la rentabilidad de la empresa.

Optimizar la capacidad productiva.

Reducir los índices de absentismo ${ }^{2} \gg$.

$\mathrm{O}$, como sucede en algunos casos, cuando se establece una justificación general, por ejemplo en el siguiente caso:

\section{«Art. 4. Retribuciones}

Gestión del tiempo de trabajo

Una de las consecuencias de los profundos cambios sociodemográficos y laborales experimentados en la última década es la creciente dificultad de los personas trabajadoras por conciliar y reorganizar de manera satisfactoria su vida personal, familiar y laboral.

El Ayuntamiento entiende que los políticas de recursos humanos han de favorecer una plantilla motivada y comprometida, puesto que esto tiene un impacto directo en el nivel de calidad y eficacia de los servicios prestados a los ciudadanos.

El Ayuntamiento asume, en este sentido, la responsabilidad de crear un nuevo escenario laboral respecto al tiempo y el espacio de trabajo, en el cual los empleados se sientan apoyados y se los favorezca, desde el entorno laboral, con la finalidad de optimizar la disponibilidad de tiempo para los diferentes ámbitos vitales.

\footnotetext{
${ }^{1}$ Convenio colectivo de trabajo de la industria del pan de la provincia de Barcelona para los años 2007-2010 (código de convenio núm. 0802525).

${ }^{2}$ Convenio colectivo de trabajo de la empresa Iveco España, SL, Irisbus Barcelona para los años 2006-2009 (código de convenio núm. 0812232).
} 
Los políticas generales y las prácticas de conciliación y flexibilización, adecuadas a los realidades individuales, deben ser los impulsores y facilitadores de este estado de bienestar y calidad de vida privada de los empleados desde la vertiente de la gestión del tiempo de trabajo, sin que esto comporte menoscabar la prestación de los servicios públicos ${ }^{3} \gg$.

Los medios que se ponen en marcha son los siguientes:

«Artículo 22.

Productividad

Instrumentos básicos:

Inversiones (nuevas tecnologías).

Adecuar racionalmente la estructura.

Nuevos métodos y, como consecuencia de estos, los tiempos resultantes; todo esto sin perjuicio de lo que se establece en el presente Convenio colectivo.

Optimización de las relaciones laborales.

Mejora de los condiciones y calidad de vida en el trabajo.

Mayor incentivación económica. ción ${ }^{4} \gg$.

Programas y sistemas de formación que permitan una mayor califica-

En algún convenio colectivo se regula la presencia de los representantes de los trabajadores, como se puede comprobar en el siguiente extracto:

«Artículo 50 .

Absentismo

La Dirección de la empresa requiere a los representantes del personal y a los trabajadores afectados por este Convenio colectivo que sean conscientes de la repercusión negativa que tanto para los intereses legítimos de la empresa como para el de los mismos trabajadores representa el absentismo actual. También les solicita que contribuyan, con una actitud responsable y oportuna, a que esta situación sea superada en beneficio de todos.

\footnotetext{
${ }^{3}$ Convenio colectivo de trabajo para el personal laboral del Ayuntamiento de Santa Coloma de Gramanet para los años 2005-2008 (código de convenio núm. 0800092). En sentido similar, art. 17 del Convenio Colectivo de la empresa Gas Natural SDG, S.A. (Código de Convenio n. ${ }^{\circ}$ 9007792) y art. 19 del Convenio Colectivo de la empresa Sociedad General de Autores y Editores para el período 2006-2008 (Código de Convenio n. ${ }^{\circ}$ 9004812).

${ }^{4}$ Convenio colectivo de trabajo de la empresa Iveco España, SL, Irisbus Barcelona para los años 2006-2009 (código de convenio núm. 0812232). En un sentido similar, art. 48 del Convenio Colectivo de la empresa Kaefer Aislamientos, S. A. (Código de Convenio n. ${ }^{\circ}$ 9003702), Convenio Colectivo del empresa Hercio de España, S.A. (Código de Convenio n. ${ }^{\circ}$ 9002482), artículo 23 del Convenio colectivo de trabajo de la empresa Aguas de Busot de Mataró, SA, Sociedad Privada Municipal para los años 2006-2008 (código de convenio núm. 0805972) y art. 51 del Convenio colectivo de trabajo de la empresa Barnices Valentine, SAU, para el año 2008 (código de convenio núm. 0800241).
} 
La Dirección de la empresa promueve acciones dirigidas a su reducción y espera que este llamamiento de atención sea comprimida y correspondida adecuadamente, y que el índice de absentismo se reduzca, cada año de vigencia del Convenio, como mínimo de un $5 \%$ respecto al año anterior. Los representantes del personal adquieren el compromiso de aportar los medios por conseguir la reducción mencionada y favorecer$l a^{5} \gg$.

Además, en algunos convenios colectivos se regulan propuestas concretas, como, por ejemplo, el teletrabajo, como se puede comprobar en los siguientes ejemplos:

«Artículo 52 bis. Complemento de teletrabajo.

El teletrabajo es aquella forma de prestación de servicios en el ámbito laboral que se caracteriza por el hecho de que el empleado desarrolla la totalidad de su jornada laboral pactada en y desde su propio domicilio.

Los empleados de la Compañía BP Oil España, S.A.E. que presten sus servicios en régimen de teletrabajo percibirán un complemento salarial de 433,60 euros brutos mensuales en cada una de las doce mensualidades ordinarias. Esta cantidad compensará, aparte de la incomodidad que pudiera suponer tener la oficina en el domicilio, los gastos ordinarios de calefacción, luz, limpieza, así como cualquier otro de similar naturaleza.

Desde la fecha efectiva de su abono dejará de percibir la Ayuda de Comer establecido en el texto del Convenio.

Con efectividad de $1 .^{\circ}$ de abril de 2006, 1. ${ }^{\circ}$ de abril de 2007 y $1 .^{\circ}$ de abril de 2008, la citada cantidad se incrementará en la cuantía equivalente al aumento general de salarios pactado para estos años.

Al mismo tiempo, y por una sola vez, el empleado dispondrá como máximo de la cantidad de 1.900,00 euros para realizar todas aquellas obras de acondicionamiento en su vivienda que estime necesarias derivadas de la especialidad de la prestación de los servicios que implica el teletrabajo. Como requisito adicional, antes de iniciar las mismas deberá recaudar aprobación del responsable del negocio y justificarlas con posterioridad ${ }^{6} \gg$.

\footnotetext{
${ }^{5}$ Convenio colectivo de trabajo de la empresa TU Group Automotive Systems, SA (Montornès del Vallès) para los años 2007-2009 (código de convenio núm. 0805461). En un sentido similar, Pacto regulador de condiciones económicas y laborales del personal funcionario del Ayuntamiento de Ribes de Freser para los años 2007-2008 (código de convenio núm. 1702352).

${ }^{6}$ V Convenio Colectivo de la empresa BP Oil España, S.A.E, (Código de Convenio n. ${ }^{\circ}$ 9008752).
} 
«Artículo 10.

Trabajo a distancia

1. El Ayuntamiento en su papel fundamental en la protección de derechos, ha de ejercer una función ejemplificadora para la sociedad en la implantación del trabajo a distancia, contribuyendo a mejorar el clima laboral, el rendimiento de los trabajadores públicos y la calidad del servicio que prestan a la ciudadanía.

2. Con el fin de perseverar en la adopción de medidas de conciliación de la vida laboral y familiar, la corporación se compromete durante el 2008 a iniciar un estudio de los puestos de trabajo susceptibles de poder trabajar en régimen de trabajo a distancia priorizando a los trabajadores que es encuentren en alguna de estas situaciones:

a) Con familiares con situación de dependencia.

b) Con problemas de movilidad reducida.

c) Con residencias alejadas.

3. Los condiciones en las que es llevará a cabo esta modalidad de trabajo se concretaran al sí de la Mesa Negociadora y se añadirán como parte integrante del presente Convenio colectivo ${ }^{7}$.

\section{Conclusiones}

En la literatura especializada no existe unanimidad sobre la definición del absentismo laboral. La mayoría de estudios y documentos sobre el tema ha partido de definiciones amplias del absentismo, utilizando el concepto horas no trabajadas totales, o bien ha excluido algunos conceptos que claramente no tienen que ver con el absentismo

Los datos disponibles sobre absentismo laboral deben ser considerados con prudencia, dada la escasez de datos estadísticos que permitan la estimación directa del absentismo. Por otro lado, la tasa de absentismo es un indicador que mide parcialmente la magnitud de la problemática.

Los países europeos con una ratio de absentismo laboral más elevado son Francia y Alemania, mientras que España supera ligeramente la media europea. Los sectores con un mayor absentismo son la química y los seguros.

En relación con España, desde el año 2000 la tasa de absentismo crece de una manera continua y es más alta en el caso de los trabajadores con jornada completa, cuanto más grande es la dimensión de las empresas y en el sector industrial. Sin embargo, el sector servicios y las pequeñas y medianas empresas son los colectivos que han registrado un mayor incremento del absentismo en los últimos años. El impacto total provocado por el absentismo laboral sobre las empresas españolas supuso un coste de casi $10.600 \mathrm{mi}-$ llones de euros en 2006, es decir, un 1,1\% del PIB.

\footnotetext{
${ }^{7}$ Convenio colectivo de trabajo del personal laboral del Ayuntamiento de Premià de Mar para los años 2008-2011 (código de convenio núm. 0805192).
} 
Sin embargo, la principal causa de absentismo laboral en España es la incapacidad temporal. Ante la incapacidad temporal los sistemas de prestaciones son muy divergentes dentro la Unión Europea. En la mayoría de países se prevé un período de espera de tres días, a partir del cual se abona un porcentaje del salario. Las empresas acostumbran a asumir el pago de los primeros días y, posteriormente, el Gobierno paga un subsidio por incapacidad temporal, que puede ser complementado por las propias empresas.

Finalmente, según la Encuesta realizada por la patronal catalana Cecot sobre absentismo laboral, tan solo el 19,5\% de las empresas tiene planes específicos para combatir el absentismo, y un $16,7 \%$ de los casos han conseguido una reducción significativa de esta problemática.

Existe un mayor grado de aplicación de estos planes en la industria (con un 24\% de las empresas, en contraste con la construcción, donde ninguna empresa encuestada aplica planes de este tipo). En particular, los planes para combatir el absentismo tienen una importancia muy notable en las empresas grandes (de más de 250 trabajadores), puesto que se aplican en un $85,7 \%$ del total. Estos planes incluyen, principalmente, medidas de mejora en la prevención de riesgos laborales, reparto eficiente de la carga de trabajo, y mejoras en la gestión y control de los recursos humanos. A distancia se sitúan actuaciones en los ámbitos de la flexibilidad de horarios, la mejora de la comunicación y la conciliación de la vida laboral y familiar.

El impacto de las medidas aplicadas es positivo, puesto que un 52,8\% de las empresas que lo han aplicado consideran que habido una reducción del absentismo. Sin embargo, tan solo un 16,7\% de las empresas han experimentado una reducción significativa de la problemática y un $39 \%$ opina que sus efectos han sido casi nulos.

Estos datos podrían sugerir que la mayoría de empresas opina que los factores que impulsan el absentismo tienen que ver con elementos externos a la empresa. De hecho, casi la mitad (un 49,7\%) señala que se deberán producir cambios en el sistema sanitario, a la vez que también se apunta (un $24,9 \%$ ) la necesidad de cambios en la cultura de los trabajadores y de la gestión de los recursos humanos (un 20\%).

\section{Bibliografía}

AA. VV.: Guía práctica para la gestión del absentismo, Egarsat, Terrassa, 2008.

Aguirre SÁdABA, A.: Análisis de absentismo en el ámbito del control de gestión del personal, Barcelona, Alta Dirección, número 9, 1980.

Dalton, Dan R.; Mesch, Debra J.: «The impact of employee-initiated transfer on absenteeism: A four-year cohort assessment», Human Relations, vol. 45 (3), 1992. 
FRAYNE, Colette A.: Reducing employee absenteeism through self-management training: A researchbased analysis and guide, Quorum Books, New York, NY, US, 1991.

JimÉNEZ GALindo J. F., ROMAY LóPEZ, R.: La gestión del absentismo por incapacidad temporal, Dykinson, Madrid, 2005.

Molinera Mateos, J. F.: Absentismo laboral. Causas. Control y análisis. Nuevas Formas. Técnicas para su reducción, Fundación Confemetal, Madrid. 2002.

OstrofF, Cheri: «The effects of climate and personal influences on individual behavior and attitudes in organizations», Organizational Behavior and Human Decisión Processes, vol. 56(1), 1993.

Ribaya Mallada, F. J.: La gestión del absentismo laboral, Editorial Montecorvo, Madrid, 1996

SMULDERS, Meter G.: «Absenteeism of part-time and full-time employees», Applied Psychology An International Review, vol. 42(3), 1993.

THARENOU, Phyllis: «A test of reciprocal causality for absenteeism», Journal of Organizational Behavior, vol. 14(3), 1993.

ÚBEDA, A. R.; LÓPEZ, M. A.: «Absentismo laboral, visión retrospectiva de los años 1974-1984», Salud y Trabajo, Número 54, 1986. 